\title{
Development of the Rat Superior Cervical Ganglion: Ingrowth of Preganglionic Axons ${ }^{1}$
}

\author{
ERIC RUBIN ${ }^{2}$ \\ Department of Physiology and Biophysics, Washington University School of Medicine, St. Louis, Missouri 63110
}

\begin{abstract}
The growth of sympathetic preganglionic axons has been studied in the fetal rat. Preganglionic axons first emerge from the spinal cord and enter the paravertebral chain of ganglia between days 12 and 13 of gestation (E12 to E13). By E14, hundreds of preganglionic neurons have sent axons into the sympathetic chain. Even at this age, the arrangement of the preganglionic axons conforms to the adult organization in a number of ways. As in maturity, these axons leave the spinal cord only through the ventral root of the segment in which their cell bodies reside. Furthermore, axons grow into the superior cervical ganglion only from the same set of spinal segments as supply this ganglion in maturity, and in correct segmental proportions, although there is a slight rostral-tocaudal lag along the spinal cord in the full establishment of the projection.

The development of appropriate projections in this system owes little to the growth of axons along stereotyped pathways. Rather, preganglionic organization apparently reflects a more general instruction that governs the relative number of axons from each spinal segment which course rostrally or caudally within the sympathetic chain. The appropriate distribution of preganglionic axons early in development suggests that a fiber's segmental level of origin biases the axon to grow in a particular direction.
\end{abstract}

The mammalian sympathetic chain is a relatively simple part of the nervous system, yet the connections within it are highly organized (Njå and Purves, 1977a; Lichtman et al., 1979, 1980). To examine how this organization develops, the growth of sympathetic preganglionic axons in the fetal rat has been studied in an isolated preparation, using horseradish peroxidase (HRP) as an axonally transported marker. Even in the early stages of outgrowth, this procedure reveals the trajectories of preganglionic axons. The results show that mature axon pathways arise directly from the initial pattern of fiber extension. In particular, axons originating in different spinal

Received April 23, 1984; Revised August 17, 1984;

Accepted August 22, 1984

${ }^{1}$ I thank Dale Purves for his support and advice throughout this study, and C. J. Forehand, R. D. Hadley, J. W. Lichtman, and J. T. Voyvodic for comments on the manuscript. Expert technical help was provided by Emily Gordon, Pat Newton, and Dorothy Dill. Thanks also to Sue Eads and Jan Wuelling for typing the manuscript, and to Vicki Friedman for help with illustrations. This work was supported by grants from the National Institutes of Health (NS-11699 and NS-18629) and from the Muscular Dystrophy Association to D. Purves.

${ }^{2}$ To whom requests for reprints should be sent, in care of Dr. D. Purves, at Department of Physiology and Biophysics, Washington University School of Medicine, St. Louis, MO 63110. segments seem biased to project in characteristic patterns from the start. The guidance of axon outgrowth in this system may thus be related to the rostrocaudal position of preganglionic cell bodies within the spinal cord. Some of the results presented here have been briefly reported (Rubin, 1982, 1983).

\section{Materials and Methods}

Animals and routine histological techniques. The procedures for obtaining timed pregnancies, manipulating fetal rats, and processing tissue for light and electron microscopy are described in the previous paper (Rubin, 1985a). The day of conception is designated $\mathrm{EO}$; birth (PO) occurs early on the 22nd day of gestation (E22). All quantitative results pertain to the sympathetic system on the right side.
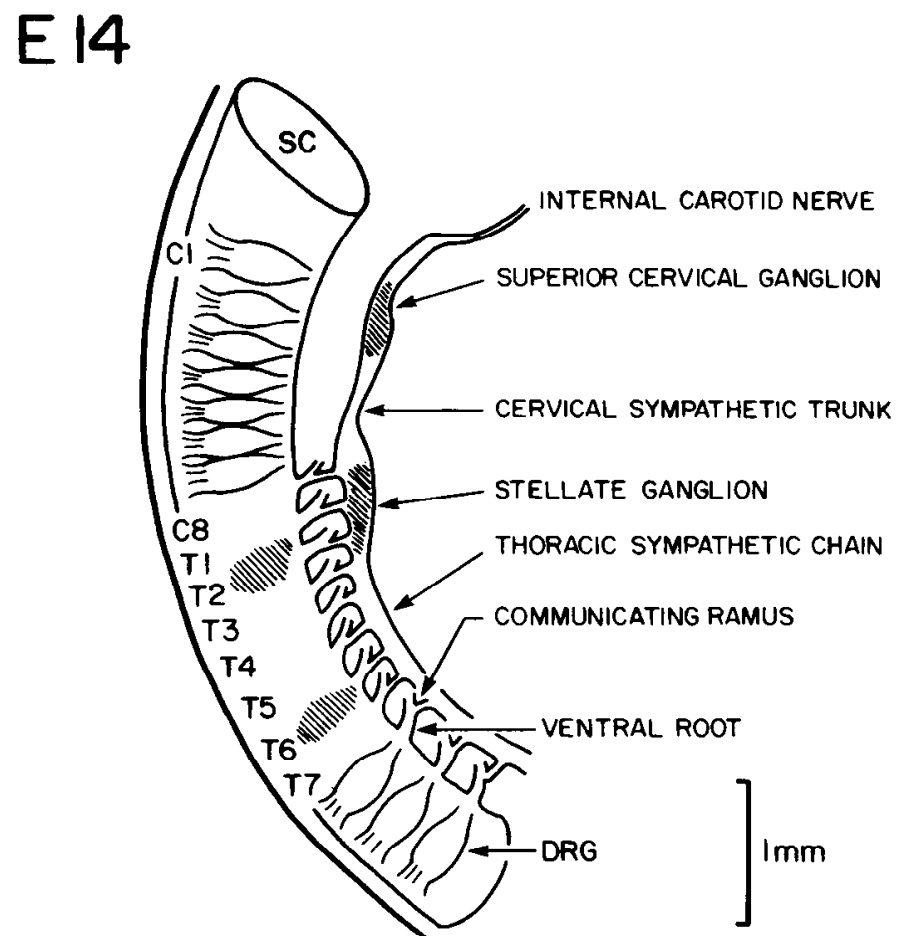

Figure 1. The sympathetic system of the fetal rat on E14, illustrating the methods used to study developing preganglionic projections, shown from a lateral view; the dorsal curvature of the fetus is to the left. Preganglionic axons grow from cell bodies in the spinal cord (SC) through ventral roots, proximal spinal nerves, and communicating rami to reach the sympathetic chain. HRP was injected into sites designated by shading (see "Materials and Methods" in Rubin, 1985a). Preganglionic neurons with axons already in the sympathetic chain were labeled by retrograde transport of HRP from either the stellate or superior cervical ganglia. Axon outgrowth was also examined with orthograde labeling after spinal injections of HRP. C, cervical, and $T$, thoracic segments, based on location of dorsal root ganglia (DRG; ganglia not shown in segments $C 8$ to $T 7$ ). 

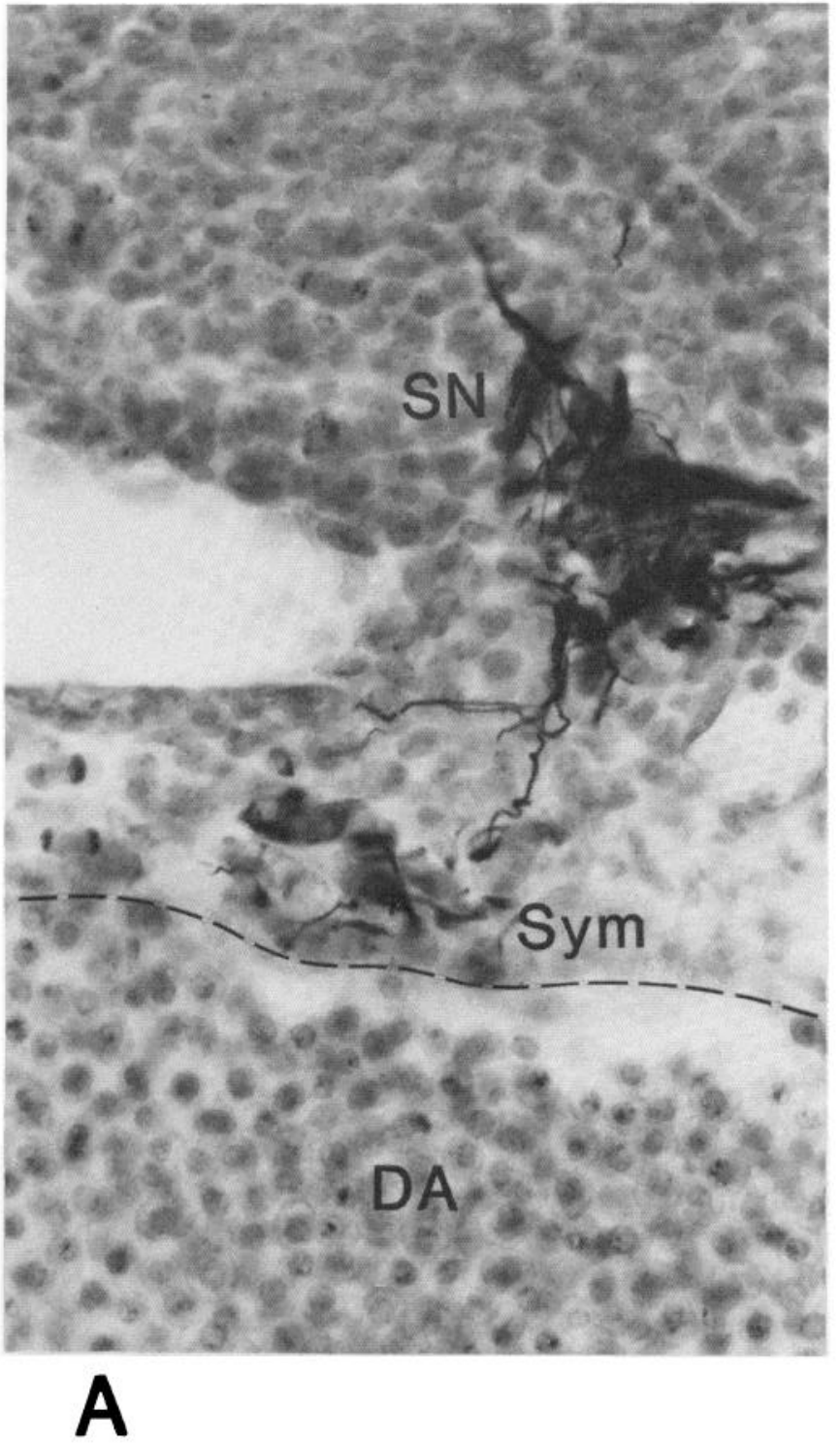
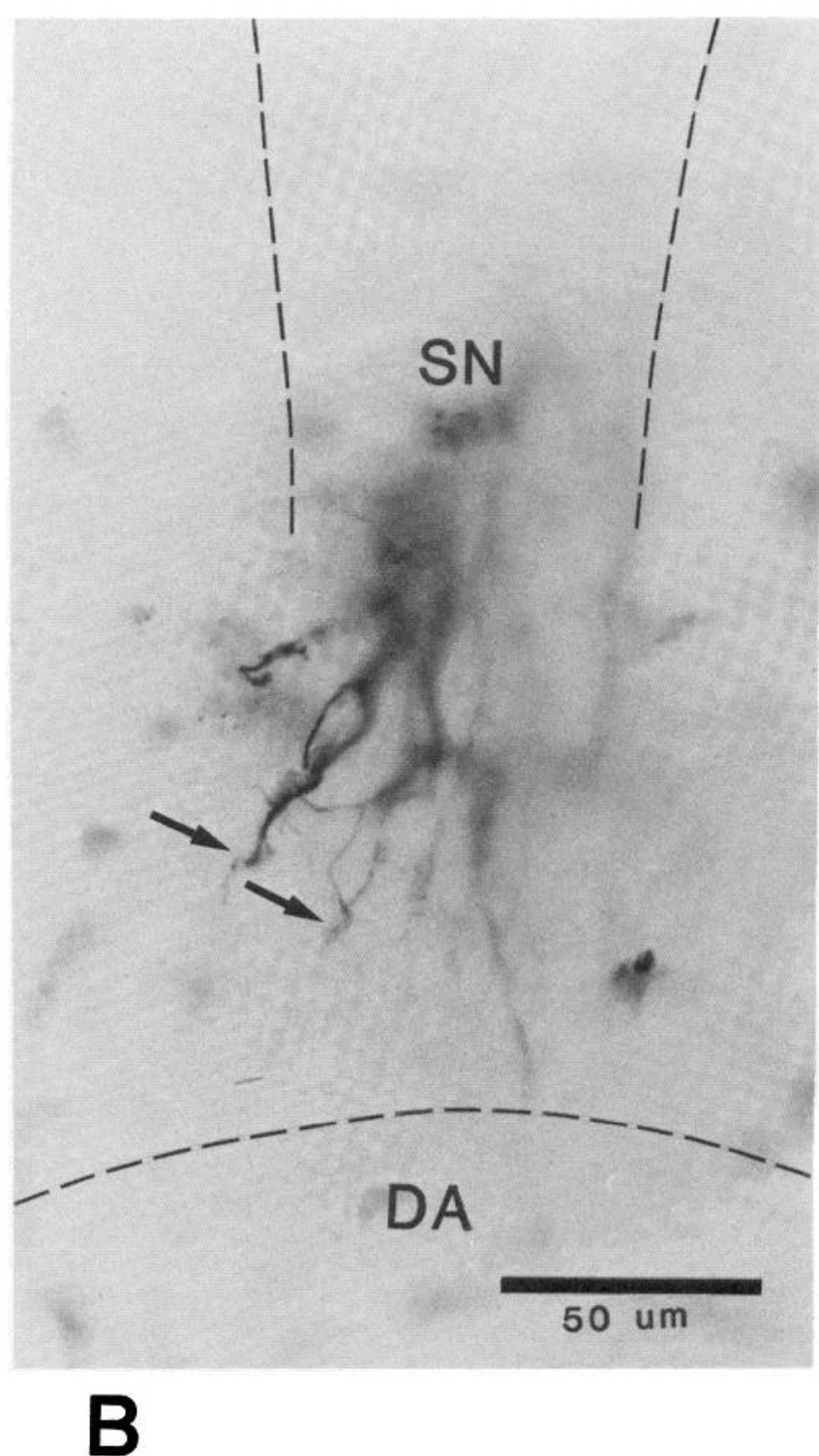

Figure 2. The initial entry of preganglionic axons into the sympathetic chain on E12. A, Horizontal section (silver stain) passing through the dorsal aorta $(D A$, filled with nucleated blood cells) at upper thoracic levels, showing cells of the thoracic sympathetic chain (Sym) and a nearby upper thoracic spinal nerve (SN). Most of the spinal nerve fibers have only grown a short distance from the spinal cord, and distinct communicating rami are absent (confirmed in serial sections). The few fibers that do cross between spinal nerves and the sympathetic chain may be the most advanced preganglionic axons, or else they are postganglionic fibers entering spinal nerves (Rubin, 1985a). B. Section through an E12 fetus in which HRP was injected into spinal segment T2. The view is equivalent to that in $A$; no counterstain was used. Orthogradely labeled axons carried by the spinal nerve (dashed lines) end near the sympathetic chain (not visible, but located as in A). The endings of some spinal axons can be seen (arrows). The calibration bar applies to both $A$ and $B$.

Horseradish peroxidase (HRP) labeling. HRP was used to label preganglionic axons in the isolated sympathetic system of fetal rats, much as has been done for motor axons in the embryonic chick (Landmesser, 1978). A solution of HRP was injected into various sites in order to orthogradely or retrogradely label preganglionic axons (Fig. 1). In most experiments, the HRP reaction product was developed after sectioning, as described previously (Rubin, 1985a). However, in this study some material was first reacted en bloc and then sectioned. These preparations were preincubated in $0.1 \%$ pyrocatechol and $0.05 \% p$-phenylenediamine (Fluka) in $0.1 \mathrm{M}$ phosphate buffer $(\mathrm{pH} 7.3)$ for 4 to $6 \mathrm{hr}$, immersed in a fresh mixture of the same reagents with $0.03 \% \mathrm{H}_{2} \mathrm{O}_{2}$ for a similar time, and then rinsed in phosphate buffer (all at room temperature; procedure modified from Hanker et al., 1977) Tissues were dehydrated in ethanol, cleared, vacuum-embedded in paraffin, and sectioned at $15 \mu \mathrm{m}$ with the upper thoracic spinal cord in transverse orientation in order to count labeled preganglionic cell bodies in the cord. Preganglionic neurons retrogradely labeled in this way were easily visible in brightfield, with no loss of staining intensity as a function of distance from the site of HRP application. However, whereas serial paraffin sections were convenient for cell counts in fetal animals, the en bloc procedure generally yielded poorer histological quality than was obtained by first sectioning and then reacting the tissue.

In neonatal rats a somewhat different procedure was used to label preganglionic neurons (see Rubin and Purves, 1980). The cervical sympathetic trunk was cut in 0- to 1-day old animals anesthetized by hypothermia, and crystalline HRP was applied to the proximal stump. After $24 \mathrm{hr}$, the animals were reanesthetized and fixed by perfusion; their spinal cords were then sectioned in the horizontal plane and processed according to the method of Hanker et al. (1977). The efficiency of HRP labeling with different application procedures and at different ages has not been evaluated; therefore, the number of labeled cells may underestimate the actual size of the preganglionic cell population. On the other hand, HRP labeling probably does provide an accurate picture of the distribution of these cells during development, as indicated by strong staining of even the most distant labeled cells, and as confirmed electrophysiologically (Rubin, 1985b). Accordingly, most comparisons have been drawn in terms of the fraction of labeled cells found in particular segments, rather than in terms of the absolute numbers of these cells. For all animals, counts of labeled cells were corrected according to the procedure of Abercrombie (1946), using cell body diameter 


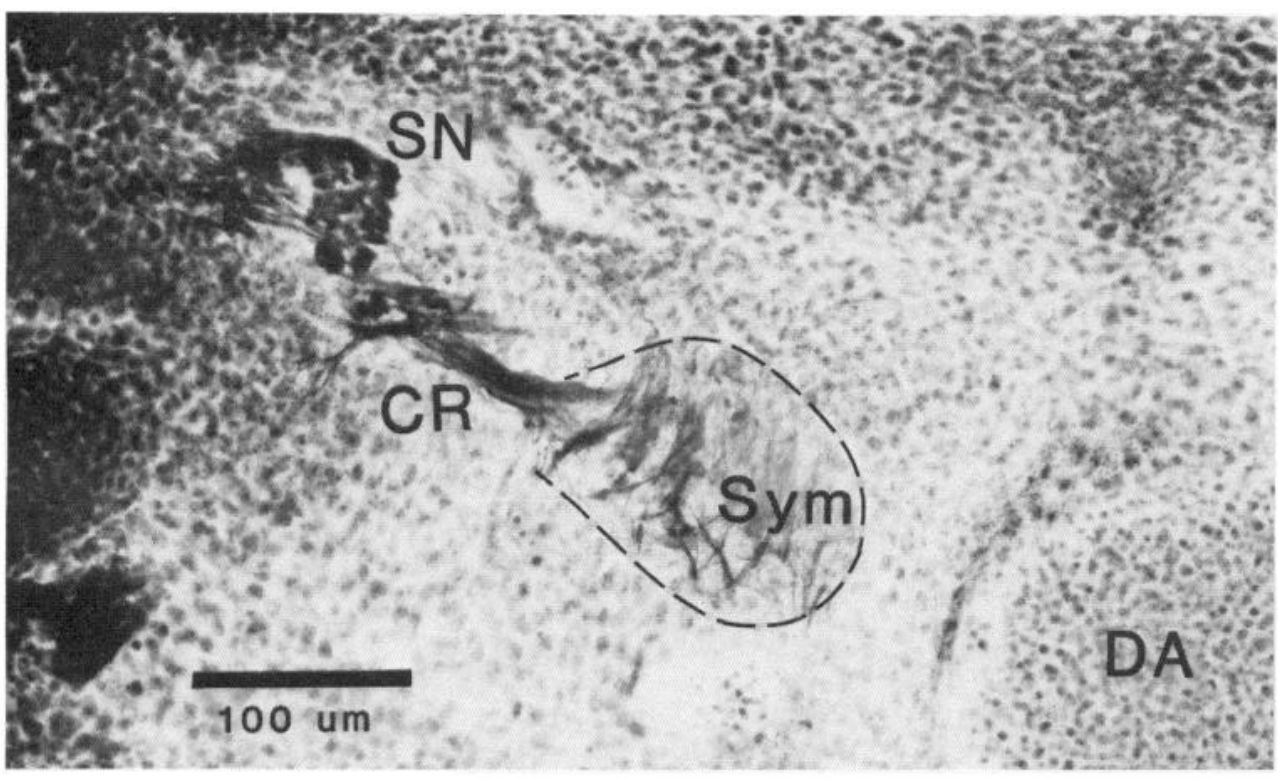

$\Delta$

Figure 3. Preganglionic axons within the sympathetic chain on $\mathrm{E} 13$. $A$, Well established communicating rami $(C R)$ convey preganglionic axons from upper thoracic spinal nerves $(S N)$ to the sympathetic chain (Sym). More caudal rami are more poorly developed at this age. Within the chain both pre- and postganglionic axons are stained (cf. Rubin, 1985a). Oblique-transverse section; silver stain. B, Camera lucida reconstruction of the rostral sympathetic chain after HRP injection into the spinal cord at level T2 (sagittal view; cf. Fig. 1). Orthogradely labeled axons enter the chain through ramus $\mathrm{T} 2$ and already extend to cervical levels of the sym. pathetic chain. The cells of the developing superior cervical ganglion thus encounter preganglionic axons as early as E13.

RAMUS

C8

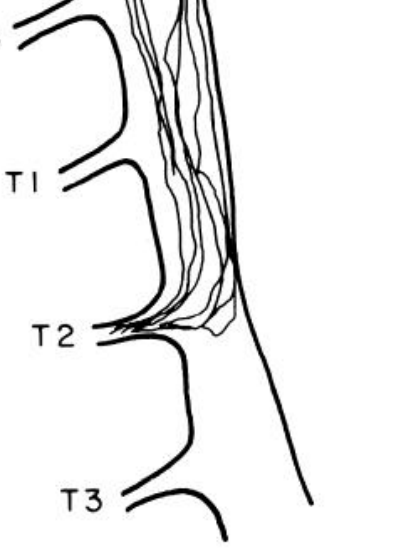




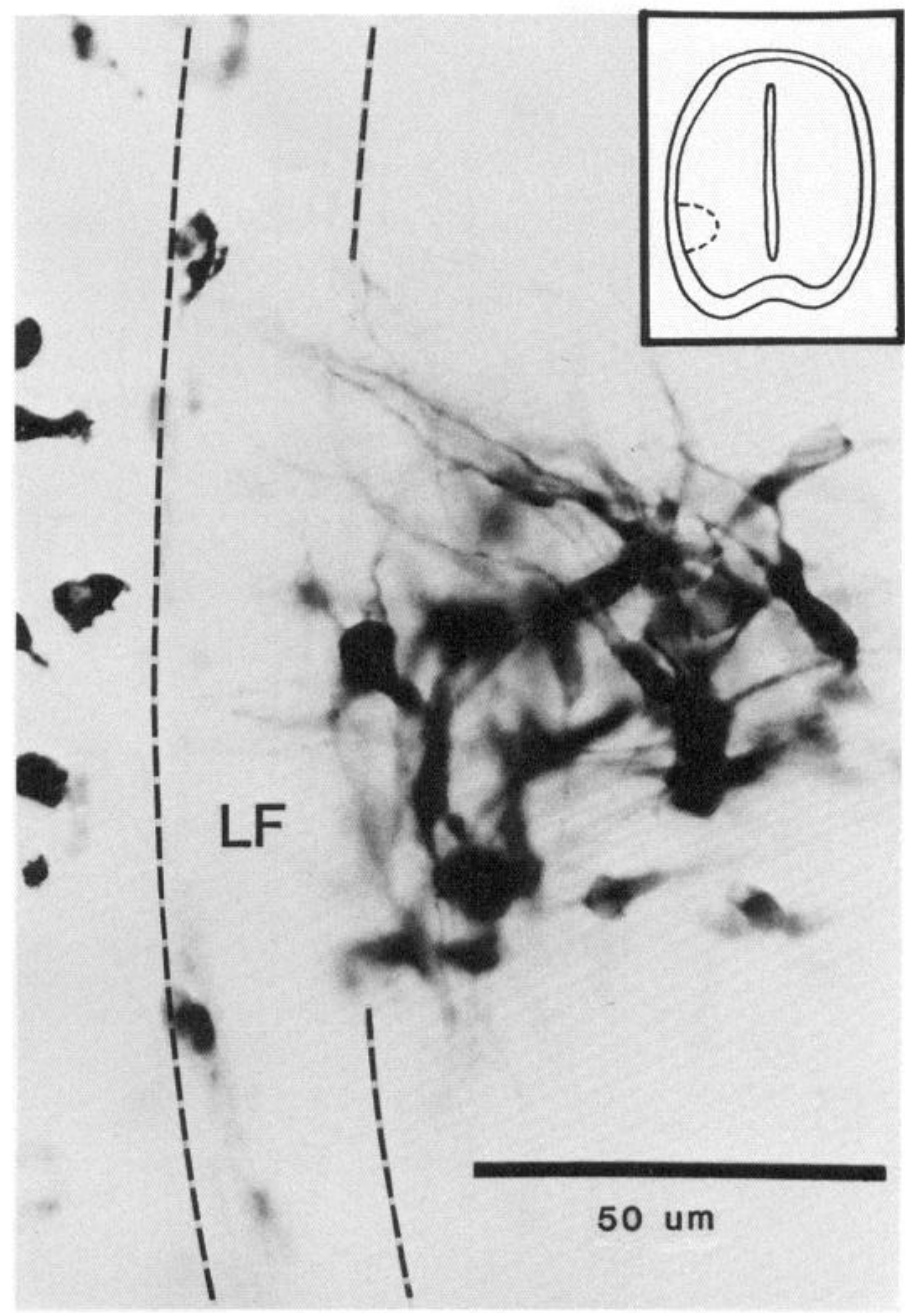

Figure 4. Preganglionic cells in segment T2, retrogradely labeled from the superior cervical ganglion, on E14. The inset shows the orientation in the transverse plane of the spinal cord. The labeled cells form a distinct cluster in the intermediolateral region of the spinal gray matter. They already bear extensive dendrites, largely arrayed in a planar (transverse) orientation (cf. Schramm et al., 1976). The dendrites penetrate into the lateral funiculus ( $L F$; edges shown by dashed lines).

in fetal preparations or nuclear diameter in neonates as the counting criterion. In assigning labeled cells to particular levels of the spinal cord, segmental boundaries were delineated by the location of dorsal root ganglia in fetuses (Rubin, 1985a) or by dorsal root entry zones (newborns). Because dorsal root ganglia may lie caudal to their corresponding spinal levels, segmental designation is sometimes inexact. However, the extent of this error is limited to less than one segment's length at thoracic levels (see Rubin and Purves, 1980).

Counts of preganglionic axons. Electron micrographs were used to determine the number of preganglionic axons in the developing cervical sympathetic trunk. After preparing tissue as previously described (Rubin, 1985a), complete cross-sections of the trunk were photographed at a primary magnification of $\times 3150$. The total number of axons was directly counted in photomontages. These counts were not adjusted for contributions made by axons originating from non-preganglionic sources; in the adult rat this correction amounts to about 9\% (Brooks-Fournier and Coggeshall, 1981).

\section{Results}

Initial entry of preganglionic axons into the sympathetic chain. On E12, the cells of the rat sympathetic chain have just begun to coalesce into distinct ganglia (Cochard et al., 1979; Rubin, 1985a). The preganglionic axons that will innervate these cells originate from neurons in the spinal cord and reach the chain of sympathetic ganglia by passing through ventral roots, proximal spinal nerves,

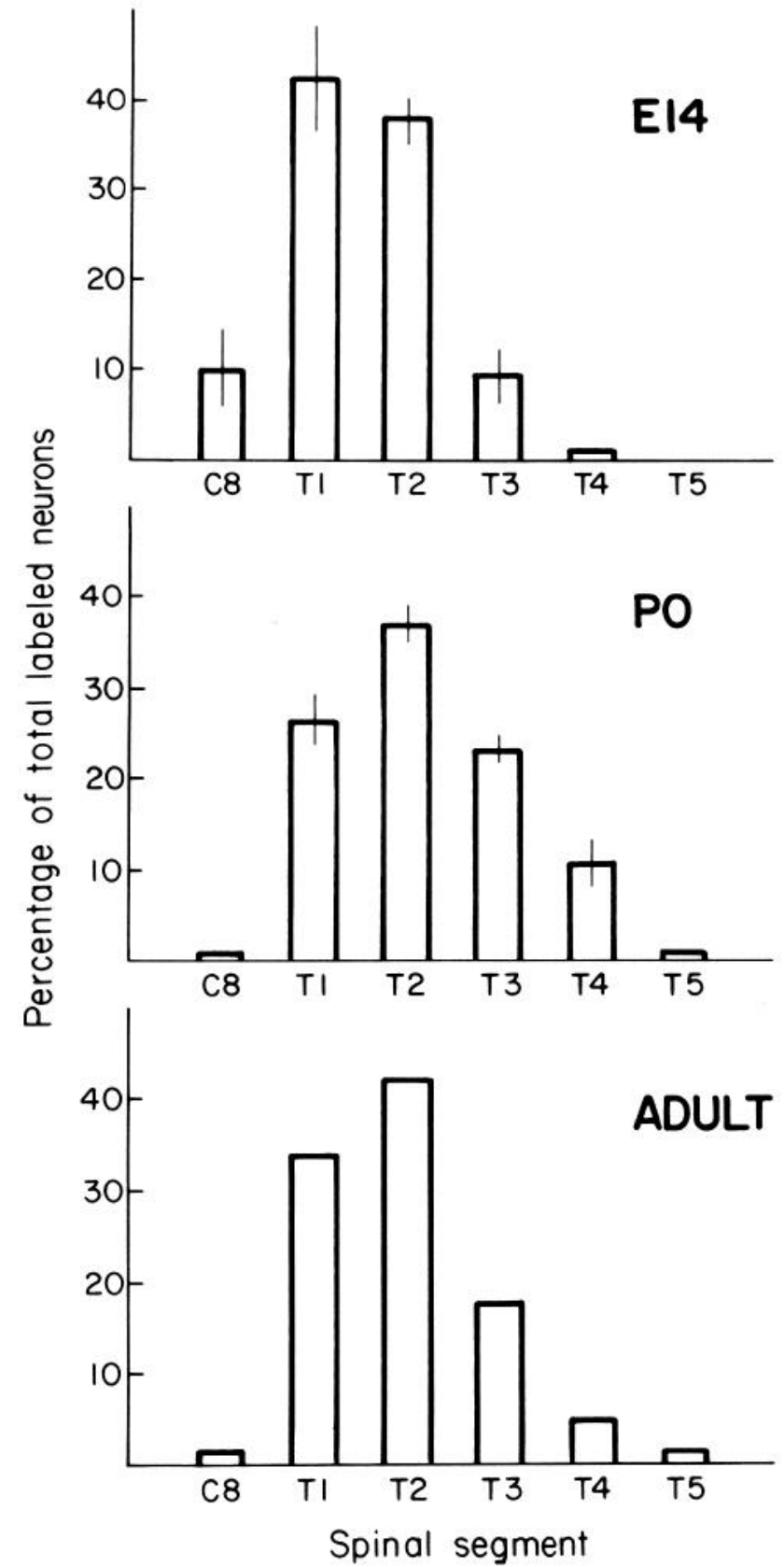

Figure 5. The distribution (mean $\pm \mathrm{SEM}$ ) of the preganglionic supply to the superior cervical ganglion at different ages, as determined by retrograde labeling with HRP. Upper panel, E14; middle panel, PO (day of birth, or E22); lower panel, adult values (from Rando et al., 1981). For E14 and PO, the distribution of cells was averaged from three animals. Although generally in correspondence, a slight caudal shift in the distribution of the labeled cells is apparent between E14 and birth.

and communicating rami; those axons that innervate the superior cervical ganglion must further ascend through the cervical sympathetic trunk (see Fig. 1). However, on E12, communicating rami are rudimentary, indicating that preganglionic axons are just starting to enter the sympathetic system (Fig. $2 A$ ). This finding from silverstained material was confirmed by HRP labeling on E12. When the enzyme was injected into spinal segments T1 or T2 (later the major source of preganglionic axons to the superior cervical ganglion), orthogradely labeled axons from these segments were found to terminate short of the sympathetic chain (Fig. $2 B$ ) or to extend only a small distance within the chain. Labeled fibers were not yet found within the cervical sympathetic system. 


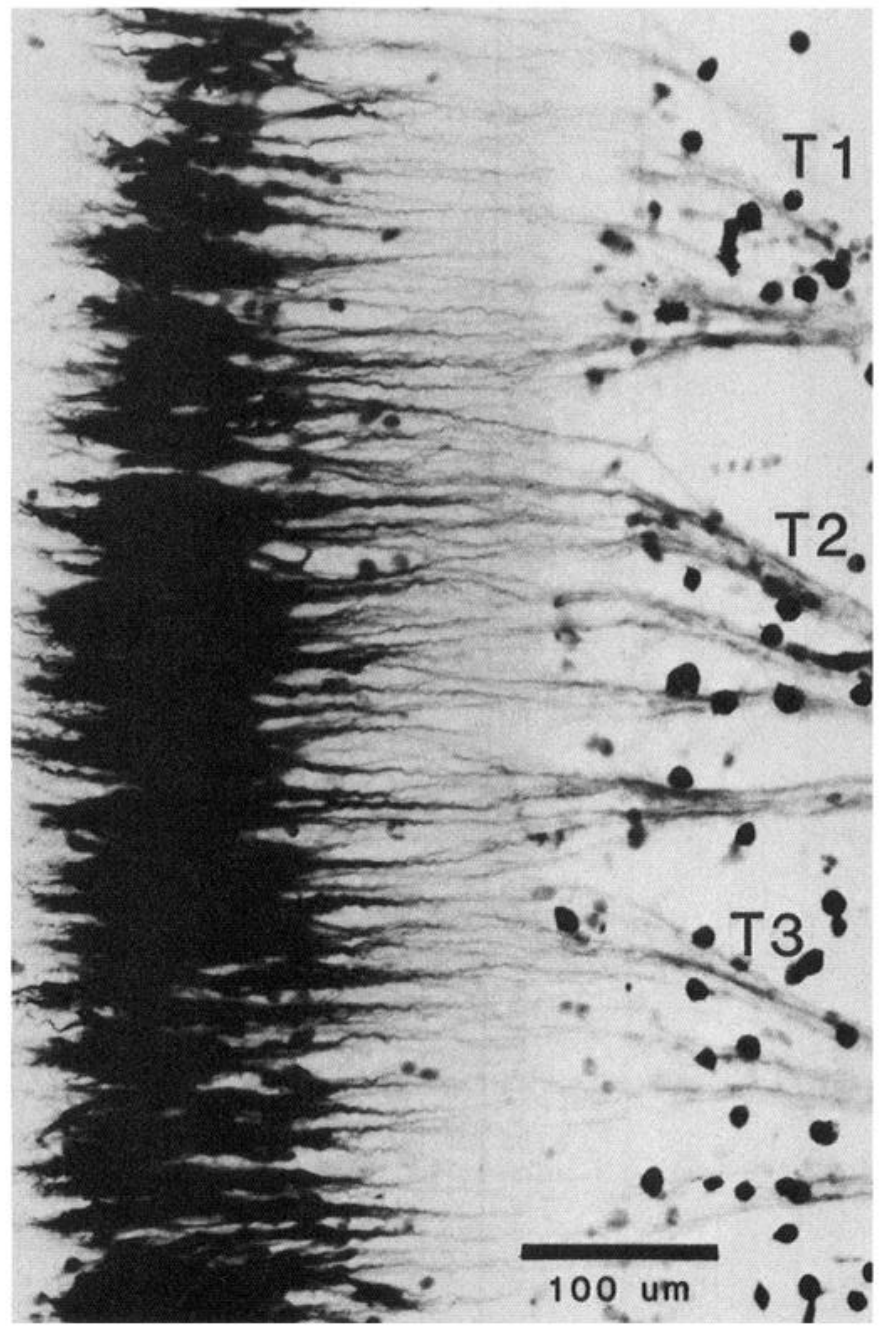

Figure 6. The spinal portion of the preganglionic pathway on E14. Sagittal $50-\mu \mathrm{m}$ section, oriented as in Figure 1: rostral is up, and dorsal is to the left. Ventral rootlets are shown converging to form ventral roots of segments T1 to T3. Preganglionic cells and axons were labeled by injecting HRP into the stellate ganglion. Dendritic trees are seen edge-on in this view (see also Fig. 4). Preganglionic axons emerge from the spinal cord through the nearest ventral root, apparently without branching.

By $E 13$, silver staining revealed distinct communicating rami at the last cervical and upper thoracic levels (Fig. $3 A$ ); thus, significant outgrowth of preganglionic axons occurs between E12 and E13. A rostral-to-caudal gradient was observed in the timing of preganglionic outgrowth, in that upper thoracic rami appeared better developed on E13 than did those located more caudally in the thorax. The penetration of preganglionic axons into the sympathetic chain by E13 was confirmed by orthograde transport of HRP from spinal segments T1 or T2. A small number of labeled axons from these segments could be followed into the sympathetic system, and as far as cervical levels of the chain (Fig. $3 B$ ). Consistent with this observation, preganglionic cell bodies in the spinal cord could be retrogradely labeled by injecting HRP into the superior cervical ganglion on E13.

Source of the early preganglionic projection to the superior cervical ganglion. On E13, very few $(<50)$ preganglionic neurons were labeled by retrograde transport from the superior cervical ganglion. The labeled cells were found in segments C8 to T2, with the bulk in T1. One day later (E14), substantially more cells (260 \pm 47 , mean $\pm \mathrm{SEM} ; n=3$ ) were labeled from the superior cervical ganglion, about one-sixth the adult number. By birth, the number of labeled cells rose to $491 \pm 153(n=3)$. In the adult rat, estimates of the number of cells projecting to the ganglion range from about 1300 (Murata et al., 1982) to 1700 (Chan et al., 1983; see also Rando et al., 1981). These results suggest that the axons of some preganglionic cells may not reach the superior cervical ganglion until after birth (but see "Materials and Methods")

On E14, nearly all cells labeled from the superior cervical ganglion were found in the intermediolateral position (Fig. 4); as in the adult rat, a small population of cells was also found medially toward the central canal (Rando et al., 1981). The labeled cells were distributed over segments C8 to T4, with about $80 \%$ of the cells in segments $\mathrm{T} 1$ and T2, and progressively fewer cells in more rostral or caudal segments (Fig. 5). In this respect, as well, the distribution of preganglionic cells supplying the superior cervical ganglion on E14 largely resembles the arrangement found in the adult (Rando et al., 1981; see also Murata et al., 1982). The small contribution from segment T5 arrives in the ganglion somewhat later than E14, apparently as part of a general increase in the relative contribution made by caudal segments to the overall projection (Fig. 5; see "Discussion"). In spite of this shift, the mature preganglionic supply arises without projections from inappropriate segments.

In addition to counting retrogradely labeled preganglionic cell bodies, an independent measure of axon growth to the superior cervical ganglion was made by counting the number of axons in the cervical sympathetic trunk, the only preganglionic pathway to the ganglion. On E14, when the trunk first becomes distinct (Rubin, $1985 \mathrm{a})$, cross-sections of the nerve contain $4301 \pm 179(n=3)$ axonal profiles. This number increases to about 6000 at birth (6080 $\pm 427, n=3$ ), and then declines in the adult to values ranging from about 4000 (Brooks-Fournier and Coggeshall, 1981) to 4800 (Murata et al., 1982; see also Aguayo et al., 1973). On both E14 and the day of birth, the number of axonal profiles within the trunk exceeds the number of preganglionic cells labeled with HRP from this nerve. Thus, preganglionic axons may branch as they travel to the superior cervical ganglion (see also below). The apparent change in the ratio of axonal profiles to labeled cell bodies with age further indicates that some branches may be lost in the prenatal period.

The pathway of preganglionic axons to the superior cervical ganglion. Preganglionic axons first grow into the cervical sympathetic system between E12 and E13; thus, on E14 the cervical projection is still in an early stage of development. At this age, retrograde HRP labeling from the superior cervical ganglion stained not only preganglionic cell bodies but their axons as well. As a result, early axonal pathways to a particular target could be directly examined.

After injecting HRP into the superior cervical ganglion on E14, ventral root fibers were labeled only at spinal levels which also contained labeled preganglionic cell bodies; the number of such labeled axons corresponded roughly to the number of labeled somata at a given level. These findings indicate that preganglionic axons emerge from the spinal cord through the ventral roots of the segments containing their cell bodies. This was confirmed by injecting HRP into the stellate ganglion, which resulted in heavy labeling of the preganglionic cell bodies and axons (Fig. 6). The labeled axons could be followed along straight paths into the ventral root at the fibers' level of origin, with no intraspinal branching in either transverse or sagittal views. Thus, from the outset the axons of preganglionic cells leave the spinal cord in a segmentally restricted fashion, as in the adult (Rubin and Purves, 1980).

Preganglionic axons projecting to the superior cervical ganglion do not appear to maintain organized relationships with one another as they pass from ventral roots into proximal spinal nerves. Thus, axons originating from different regions of a given segment mingle extensively once they leave ventral rootlets and converge in the spinal nerve. More distally, these axons often cross over one another as they turn from their spinal nerve into the communicating ramus (Fig. 7). A few fibers appear to overshoot this turn during growth, reverse direction, and only then enter the ramus.

Whereas such pathways indicate that preganglionic axons are not 


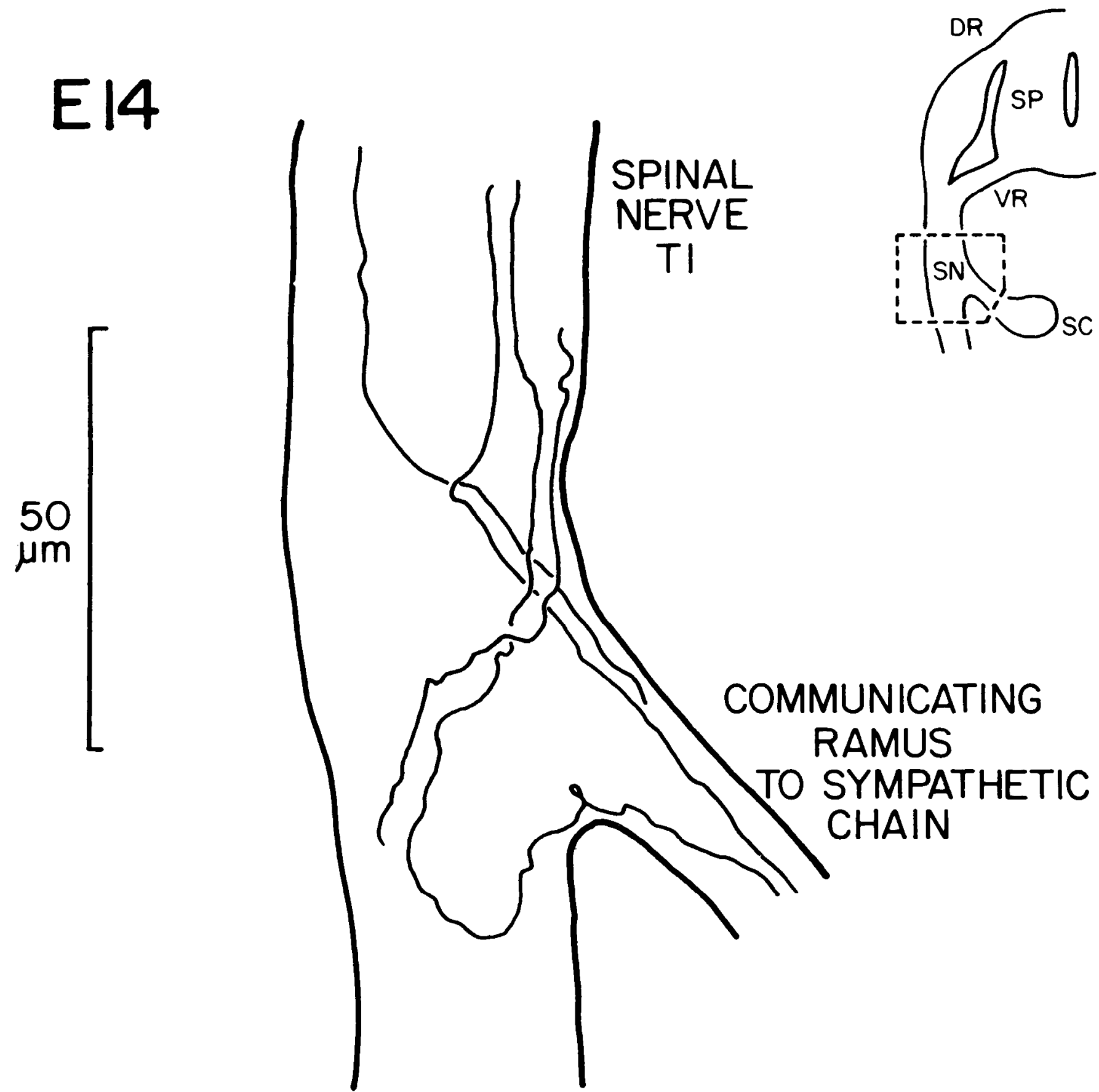

Figure 7. Routes taken by preganglionic axons as thcy approach the sympathetic chain (E14). Camera lucida drawing of a single $50-\mu \mathrm{m}$ section, transverse view (see area of inset enclosed by dashed box). The axon fragments shown here originated from segment $\mathrm{T} \uparrow$ and were labeled retrogradely from the superior cervical ganglion. Axons from a given segment travel through the width of the spinal nerve, in no apparent spatial order. Some fibers overshoot the communicating ramus and reverse course before entering this nerve. All axons shown then pass through the ramus and into the sympathetic chain (see Fig. 8). SP, spinal cord; DR, dorsal root; VR, ventral root; SC, sympathetic chain; SN, spinal nerve.

highly organized in proximal spinal nerves, these fibers grow in a more restricted manner as they proceed through the communicating rami. As early as E14, axons destined for the superior cervical ganglion course primarily along the rostral edge of the rami in segments $C 8$ to T4, in well defined bundles (Fig. 8). Very few of these axons travel through caudal portions of the rami.

As fibers projecting to the superior cervical ganglion reach the sympathetic chain, the organization that appeared in the rami is lost. Much as axons arising from a single segment mingle within proximal spinal nerves (Fig. 7), axons from different segments disperse and mix with one another across the full width of the sympathetic chain (Fig. 8). The detailed routes followed in the chain by individual axons are highly variable and appear to be independent of the routes taken by other fibers. Axons in the chain may run together for distances of $100 \mu \mathrm{m}$ or more and then diverge to travel with different fibers; even axons that originate in the same segment and project in common to the superior cervical ganglion show no particular tendency to travel together. Consistent with such behavior, electron microscopy showed that preganglionic axons on E14 are not yet confined by Schwann cell sheaths (see also Aguayo et al., 1973). Thus, early in development, these fibers seem to change relationships freely as they pass through the sympathetic chain.

Labeling with HRP confirmed that fetal preganglionic axons give off a number of collaterals (Fig. $9 A$; see also above). Many fibers 


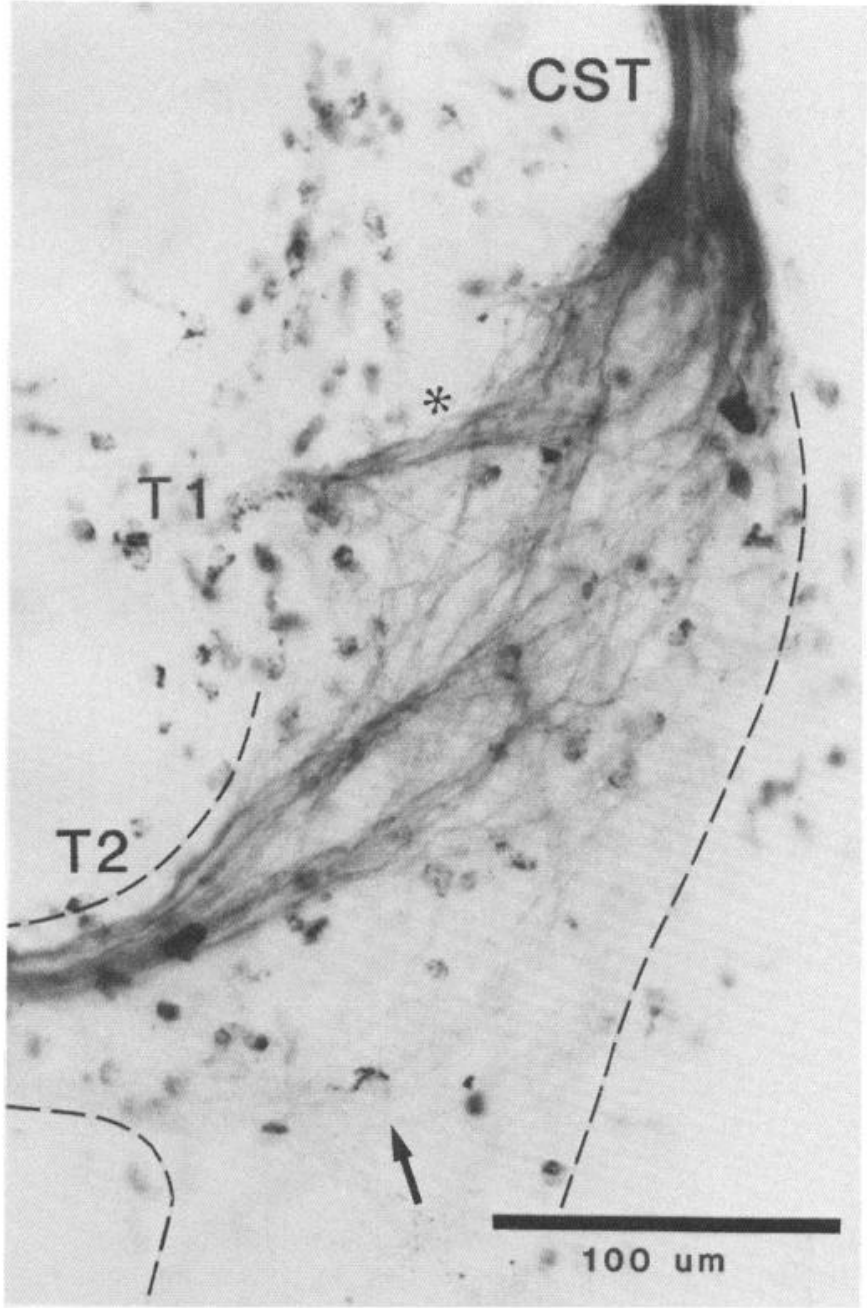

\section{A}

Figure 8. Preganglionic axons within the sympathetic chain, retrogradely labeled from the superior cervical ganglion (E14). $A$, Labeled fibers in the T2 ramus (T2) as they enter the sympathetic chain at the level of the stellate ganglion (boundaries shown by dashed lines). Orientation is as in Figure 1,50 $\mu \mathrm{m}$ section. The labeled fibers are concentrated near the rostral edge of the ramus and run parallel to one another. Only a few labeled fibers (arrow) emerge from the caudal part of the ramus; otherwise, the caudal region does not carry axons that project to the superior cervical ganglion (cf. Fig. 12). CST, cervical sympathetic trunk; $T 1$, site of $T 1$ ramus. $B$, Detail of $A$. Asterisks indicate the same axons in both $A$ and $B$. As fibers traverse the stellate ganglion, they lose the parallel organization seen in the rami. Here, one axon from segment T2 runs rostrally and then makes an abrupt bend (open arrow), while another T2 fiber (arrowheads) follows a completely separate path. Such divergence is widespread and, thus, axons from different segments intermix extensively. In spite of this apparent disorganization, all of the fibers shown here eventually reach the superior cervical ganglion.

projecting to the superior cervical ganglion on E14 branch within the stellate ganglion, and their collaterals tend to maintain the general rostral course of the parent fibers. A single axon on E14 may give off several branches that pass through the cervical sympathetic trunk and go on to ramify within the superior cervical ganglion. Other collaterals of the same fiber may remain in the stellate ganglion to form local ramifications (Fig. 9B). Preganglionic axons generally do not branch before they enter the sympathetic chain, or within the cervical sympathetic trunk itself. Evidently, during early development the formation of both collateral projections and local ramifications is favored in areas that contain potential target cells.

In summary, the projection to the superior cervical ganglion is well organized in several respects on E14. The preganglionic axons forming this projection appear to follow relatively independent pathways, yet maintain an overall rostral direction within the sympathetic chain.

Axon outgrowth as a function of spinal level of origin. To gain a more general picture of how preganglionic fibers are organized early in development, axons were orthogradely labeled from a range of segments on E14 (Fig. 1). As on E13 (Fig. 3B), injections of HRP that were confined to a single segment labeled axons only in the corresponding ventral root, confirming the segmental pattern of axon emergence (see also Fig. 6). Orthograde labeling also showed that the distribution of preganglionic axons within the sympathetic chain is related to the axons' segmental level of origin. For example, on E14, fibers from segment $T 1$ or $T 2$ course predominantly in the rostral direction within the sympathetic chain (Fig. 10); only a small percentage of the axons arising from these segments turn caudally from their level of entry into the chain. As expected from retrograde labeling experiments (cf. Fig. 5), many axons from segments T1 and T2 on E14 could already be traced to the superior cervical ganglion. No special organization of these fibers was evident within the ganglion; single axons were found to extend through its full length, without confinement to any particular ganglionic region. On E14 a small number of labeled T1 and T2 axons could already be traced into the internal carotid nerve, a largely postganglionic pathway (cf. Perri et al., 1970).

In contrast, HRP injected into spinal segments T5 or T6 at the 
E 14

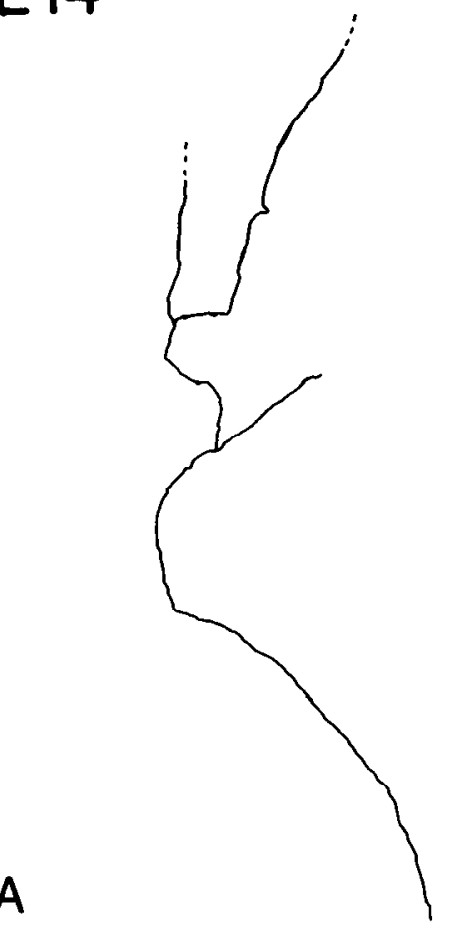

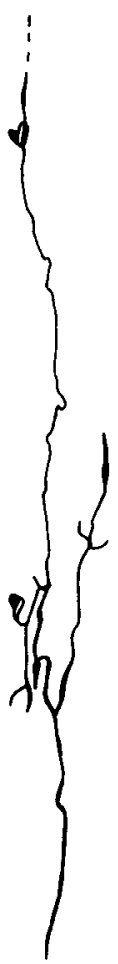
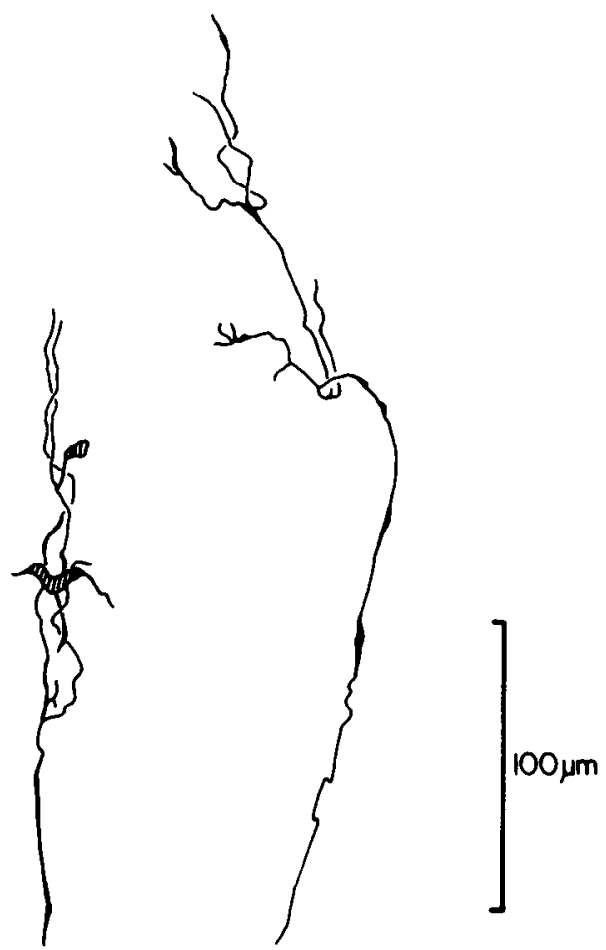

Figure 9. Branching patterns of preganglionic axons within the sympathetic chain (E14). Rostral is up. $A$, An axon retrogradely labeled from the superior cervical ganglion, passing through the stellate ganglion. This fiber originates from segment T1. Its branches maintain a generally rostral course; dashed lines indicate branches that enter the cervical sympathetic trunk. B, Other E14 preganglionic axons labeled orthogradely from segment T2 (see Fig. 1 ). This procedure often provided better staining of fibers near their origin. Some collaterals run rostrally through the stellate ganglion and into the cervical sympathetic trunk (dashes), while other processes form local arborizations in the stellate ganglion. Shaded areas are membrane expansions often seen along or at the tips of fetal preganglionic axons.

same age revealed a rather different type of projection. Axons from these segments generally course in the caudal direction, and some already extend into the rudimentary splanchnic nerves on E14 (Fig. 10). No fibers projecting rostrally from segments T5 or T6 could be traced as far as the cervical sympathetic trunk. Although orthogradely labeled fibers may fade and become difficult to trace far from an injection site, the apparent failure of axons from segments T5 and T6 to project more rostrally than the stellate ganglion is consistent with the observation that HRP injecled into the superior cervical ganglion on E14 did not label preganglionic cell bodies in these segments (Fig. 5). The longitudinal projection of axons from different spinal levels in several experiments is summarized in Figure 11. Axons from T3 and T4 presumably have an intermediate type of distribution, with more equal numbers projecting rostrally and caudally. Regardless of their segment of origin, axons arising from a given spinal level disperse across the entire width of the sympathetic chain as they course rostrally or caudally.

The injection of HRP into a given spinal segment probably labels a representative sample of the preganglionic axons originating from that level, without regard to the axons' ultimate destination. The results of such experiments extend the correlation noted earlier between the disposition of fibers within a communicating ramus and the direction these axons pursue within the sympathetic chain. Thus, on E14 preganglionic fibers in the caudal portion of the T2 ramus run primarily in the caudal direction or ramify locally once they enter the sympathetic chain (Fig. 12), much as axons that pass through the rostral portions of this ramus tend to project rostrally (e.g., to the superior cervical ganglion; Fig. 8). A similar arrangement is seen at the level of segment $\mathrm{T} 6$, although many more tibers are found within caudal bundles of the T6 ramus than of the T2 ramus (cf. Fig. 10). These findings suggest that axons projecting caudally are guided by the same general principles as those that direct other axons rostrally in the sympathetic chain, and emphasize the high level of organization that exists in the early preganglionic projection.

\section{Discussion}

Many studies of sympathetic development have used biochemical assays of neurotransmitter-related enzymes or relatively nonspecific anatomical techniques to follow the growth of preganglionic axons. In the present study, developing axons have been selectively stained with HRP, a method that provides a more direct view of preganglionic fibers as they leave the spinal cord and travel to targets in the chain of sympathetic ganglia.

The timing of preganglionic growth into the sympathetic chain. Orthograde and retrograde HRP labeling, as well as silver staining and axon counts, indicates that preganglionic axons first enter the rat sympathetic chain on $E 12$, extend into cervical levels of the chain by $E 13$, and by $E 14$ form a substantial projection to the superior cervical ganglion. The first emergence of these axons from the spinal cord coincides generally with the end of proliferation in the preganglionic population (Nornes and Das, 1974).

The timing of preganglionic axon growth within the sympathetic chain described here stands in contrast to previous estimates based on assays for choline acetyltransferase, an enzyme marker for cholinergic axon terminals. The present results show that on E14 at least one-sixth the adult number of preganglionic cells project to the rat superior cervical ganglion, yet in mice of equivalent maturity, only "extremely low levels" of ganglionic acetyltransferase activity were found (Coughlin et al., 1978; see also Black et al., 1971). This tinding indicated that preganglionic axons arrive in the ganglion at a significantly later stage of development than is actually the case. The limitation of the acetyltransferase assay as an index of preganglionic axon development is underscored by other observations showing that cholinergic synaptic transmission appears almost as soon as 


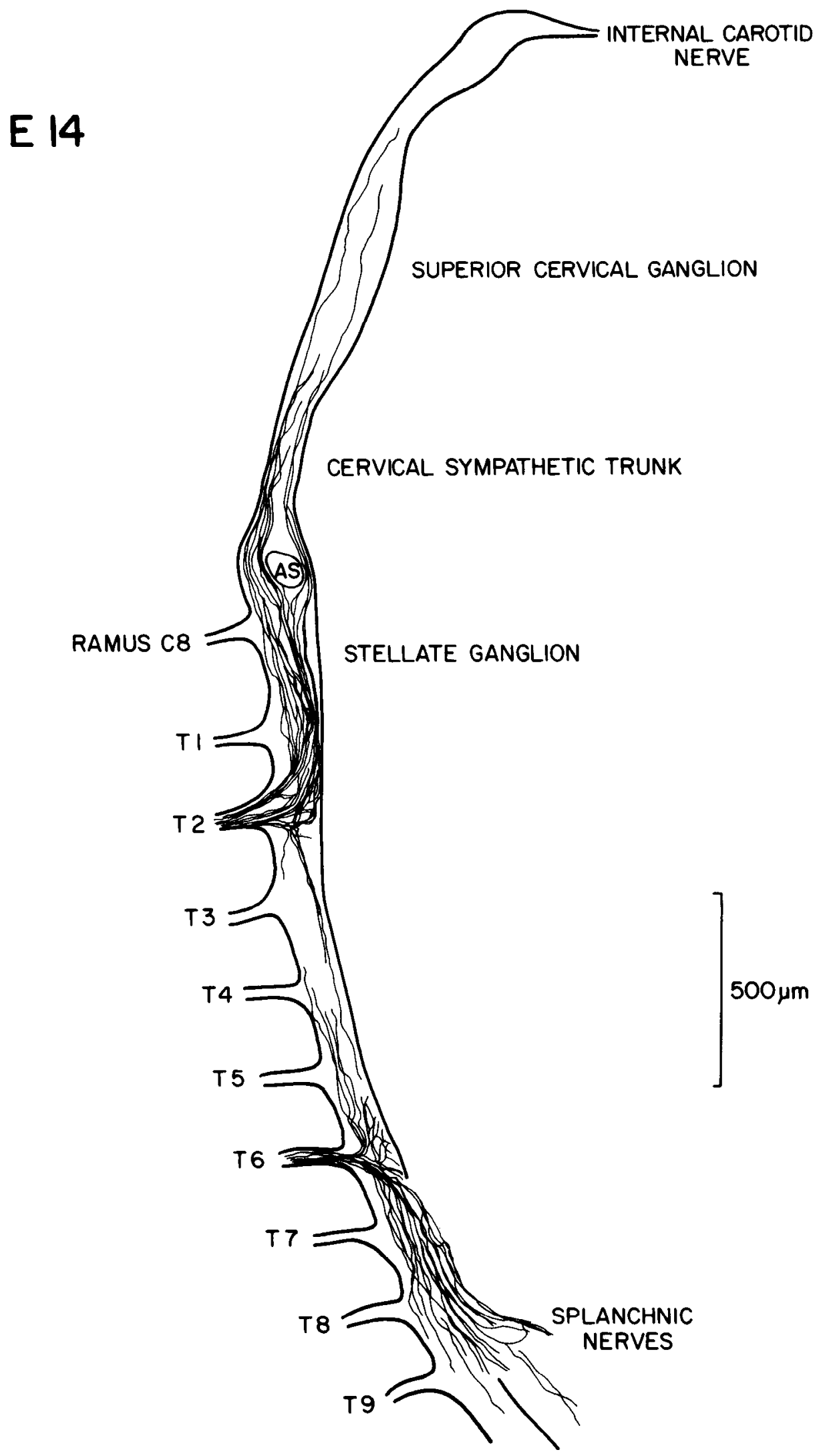

the first preganglionic axons reach the superior cervical ganglion, around $\mathrm{E} 13$ in the rat (Rubin, 1985b).

The growth of individual preganglionic axons. The outgrowth of preganglionic axons does not seem to involve strict associations
Figure 10. Preganglionic projections from specific spinal segments demonstrated by orthograde labeling (E14). Camera lucida reconstruction of serial sagittal sections, oriented as in Figure 1. The results from two separate experiments are combined in this figure. In one case, HRP was injected into spinal segment T2; in the other, the injection was made into segment T6. Orthogradely labeled fibers in both instances emerge from the cord only through the ventral root at the level of injection. Axons from T2 nearly all course rostrally, and some can be followed to the superior cenvical ganglion (cf. Fig. 5). Axons from segment T6 show a stronger projection in the caudal direction, and many of these fibers have already contributed to the splanchnic nerves. AS, ansa subclavia. between particular fibers. Even axons arising from the same segment or projecting to a common target (e.g., the superior cervical ganglion) do not bear any consistent relationship to one another. Fibers cross and meander extensively along most peripheral pathways; indeed, 


\section{E14}

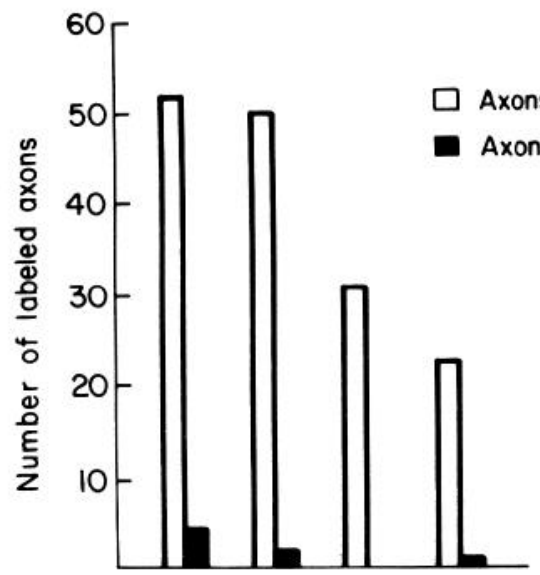

T1 /T2 injections
Axons projecting rostrally

Axons projecting caudally

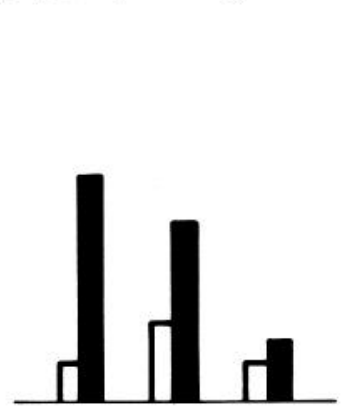

T5/T6 injections
Figure 11. The trajectory of preganglionic axons within the sympathetic chain, as a function of their segment of origin (E14). The direction taken by preganglionic axons was determined by injecting HRP into selected spinal cord segments (cf. Fig. 10). In all cases, preganglionic axons were labeled only in a single ventral root at the level of injection. The numbers of orthogradely labeled fibers were counted in the sympathetic chain at levels two segments rostral and two segments caudal to the level of injection. Each pair of bars in the histogram indicates the outcome of an individual experiment. In four animals, injections were made at the T1 or T2 level; in three others, injections were placed at T5 or T6. Note that one of the T1/T2 cases showed no caudal projection. These results indicate that preganglionic axons from different levels project characteristically within the chain, even in the early stages of outgrowth.

some axons make essential turns only after reversing their course (Fig. 7). Such variability occurs early in the development of the preganglionic projection and, thus, probably represents the actual course of axon extension.

Rather, the regulated feature of preganglionic axon outgrowth appears to be the numbers of axons from each segment that are allocated to run rostrally or caudally within the sympathetic chain, and the distance that these axons project in the chain (see also Lichtman et al., 1980). The directional control of axon growth seems especially apparent within communicating rami; here preganglionic fibers bundle together in an arrangement that is closely related to their subsequent rostral or caudal course in the sympathetic chain (Figs. 8 and 12).

Regulation of preganglionic axon growth is also evident in the distribution of collateral branches. Even on E14, fibers often branch within the ganglia of the sympathetic chain, whereas little branching occurs within axon tracts such as spinal nerves or the cervical sympathetic trunk (cf. Schäfer et al., 1983). The apparent reduction in the number of collaterals per preganglionic cell after E14 (cf. Aguayo et al., 1973) may reflect the outcome of competition between these axons for some aspect of their target cells (Purves and Lichtman, 1980). It is interesting to note that the axons of fetal ganglion cells remain unbranched in the same environment that favors preganglionic branching (Rubin, 1985a), indicating that the growth of these different axon types is to some degree separately controlled.

The development of adult sympathetic organization. Many mature features are evident in the sympathetic system as early as E14, soon after the initial outgrowth of preganglionic fibers. At this age, the preganglionic population is already limited to appropriate nuclear locations within the spinal cord and is divided into segmental pools, each of which projects from the spinal cord through a single ventral root and communicating ramus (cf. Rubin and Purves, 1980). Moreover, the preganglionic outflow of given segments on E14 is distributed rostrally and caudally in the sympathetic chain according to the

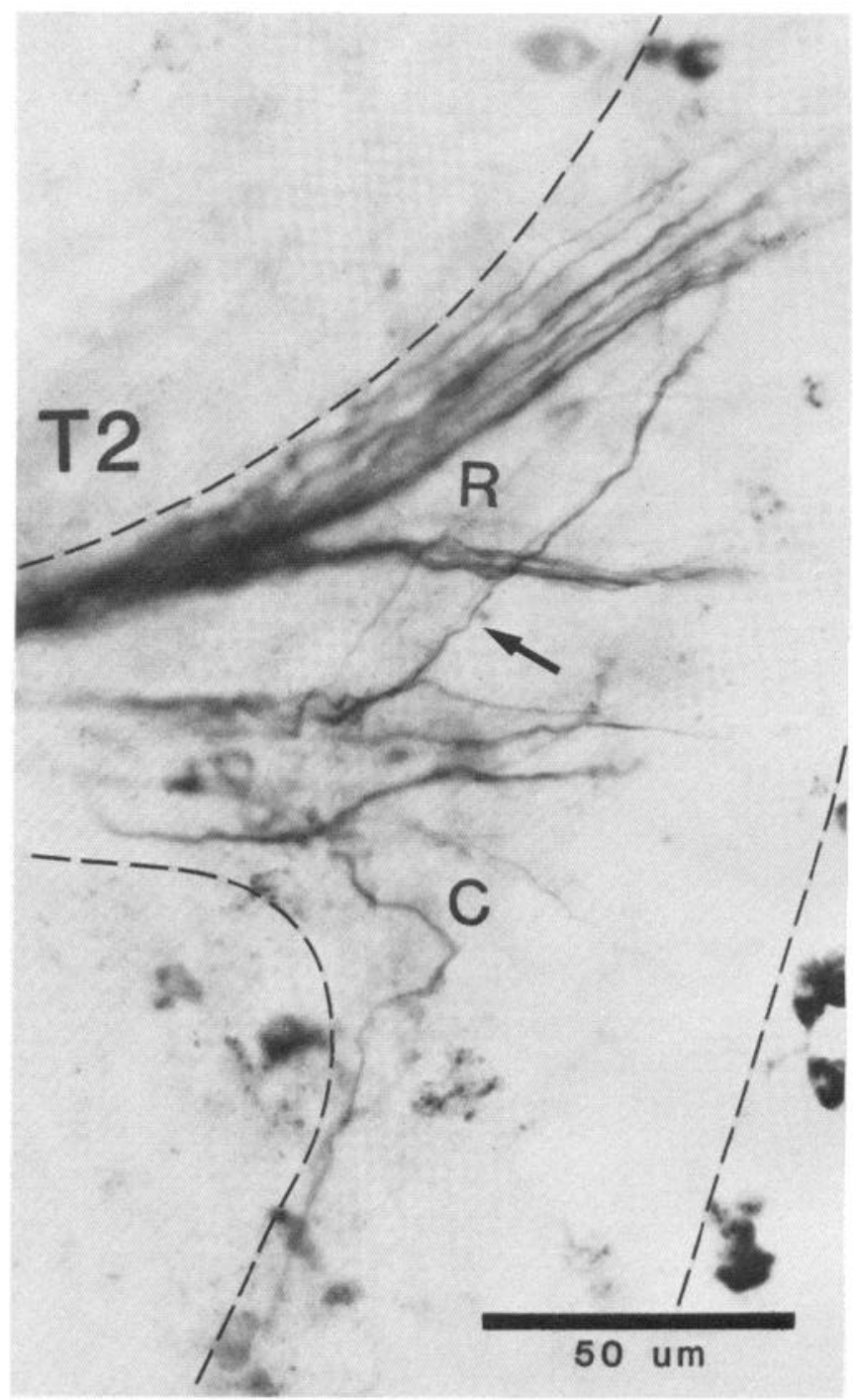

Figure 12. Preganglionic axons entering the sympathetic chain on E14 (sagittal section). Rostral is up (cf. Fig. 1). These fibers in ramus T2 were orthogradely labeled by HRP injected into the spinal cord and presumably represent the full complement of preganglionic axons emerging from the cord at this level. Within the communicating ramus (left) the axons are grouped into a number of bundles. In contrast to the arrangement of labeled axons seen after injecting HRP into the superior cervical ganglion (Fig. 8), fibers here are labeled in the caudal as well as the rostral portion of the ramus. Axons carried by rostral bundles $(R)$ tend to project rostrally in the chain, whereas axons in caudal bundles $(C)$ project caudally. Small numbers of fibers may cross between the bundles of the ramus (arrow; see also Fig. 8). Portions of the ramus that overall seem to carry few preganglionic axons may be dominated by postganglionic axons, since pre- and postganglionic axons run through a common sympathetic ramus in the rat, and by E14 considerable postganglionic outgrowth has already occurred (Rubin, 1985a). Dashes outline the ramus and sympathetic chain.

adult pattern (Lichtman et al., 1980). As a consequence, on E14 the preganglionic supply to a specific target, the superior cervical ganglion, is already restricted to the proper set of spinal cord segments; there was no evidence of a transient preganglionic projection from other segments as apparently occurs in the chick (Levi-Montalcini, 1950).

Although appropriate segments project to the superior cervical ganglion on $\mathrm{E} 14$, the proportions of the total projection arising from individual segments shift slightly in the caudal direction between E14 and PO (Fig. 5). This shift presumably reflects a rostral-to-caudal gradient in the timing of preganglionic axon initiation along the spinal 
cord. Whereas the most rostral thoracic segments probably have generated their full complement of preganglionic neurons by E14, such cells in more caudal thoracic segments may still be proliferating (Nornes and Das, 1974). The projection from caudal segments may thus be relatively under-represented on E14.

The early establishment of several mature features of sympathetic organization argues against a developmental scheme in which imprecise embryonic projections are eliminated to create the adult pattern. The substantial changes that do occur within the projection-including preganglionic cell death (Oppenheim et al., 1982), the loss of axonal branches (see above), and synaptic rearrangement within the target (Lichtman and Purves, 1980)-appear to concern relatively late quantitative adjustments between pre- and postsynaptic cells rather than the qualitative selection of these populations.

Axon guidance and synapse formation in the sympathetic system. The regulation of axon extension rostrally or caudally from particular spinal segments determines the overall availability of presynaptic axons to the superior cervical ganglion and to other ganglia at thoracic and lumbar levels of the sympathetic chain (see Lichtman et al., 1980). Evidently, an axon's segmental level of origin influences the direction the fiber will pursue as it grows within the sympathetic chain (Fig. 11). In the development of the somatic motor system as well, a relationship has been found between the position of a neuron's cell body and the peripheral path taken by its axon: motor neurons occupying different nuclei in either the transverse or the longitudinal axes of the spinal cord send their axons to different targets (Lance-Jones and Landmesser, 1981; Smith and Hollyday, 1983). Transverse distinctions may also be important in the growth of preganglionic axons, judging from the characteristic projections seen in maturity arising from the different preganglionic nuclei of a given segment (Dalsgaard and Elfvin, 1979; Nadelhaft et al., 1980).

Beyond the assignrnent of particular preganglionic fibers to ganglia at different levels of the sympathetic chain, organized connectivity in the sympathetic system involves a high degree of synaptic specificity within each ganglion. Different groups of superior cervical ganglion cells (distinguished by the peripheral destination of their axons) are innervated by preganglionic fibers that arise from systematically different subsets of the spinal segments that supply innervation to the ganglion as a whole; nonetheless, such cells are intermingled throughout the mature ganglion (Njå and Purves, 1977a; Lichtman et al., 1979). Fetal ganglion cells seem to be arranged in the same manner as in the adult, since cells within the ganglion do not change relative positions after E14 (Rubin, 1985a). Furthermore, from their first arrival, individual preganglionic axons appear to grow into every region of the superior cervical ganglion. Thus, appropriate synaptic partners seem to come together without need of any regional organization or special axon trajectories within the ganglion. The temporal order of preganglionic axon ingrowth also seems unlikely to guide selective synapse formation in the superior cervical ganglion: in spite of a small delay in the arrival of axons from caudal segments, the projection formed within 1 day of the first axons' arrival (E13 to $E 14$ ) represents preganglionic cells distributed essentially in the adult segmental pattern. Consequently, a nearly complete segmental range of axons is available in the ganglion as synaptogenesis occurs (Rubin, 1985b), particularly for the many ganglion cells that are generated after E14 (Rubin, 1985a).

These considerations suggest that synapse formation in the sympathetic system involves a selective mechanism that discriminates between preganglionic axons with different levels of origin (Rubin, 1985b; see also Njå and Purves, 1977a, b, 1978; Purves et al., 1981). The position of the preganglionic cell body in the spinal cord is thus correlated not only with the directional guidance of the cell's axon in the periphery but also with the axon's choice of synaptic partners once it enters a particular ganglion.

\section{References}

Abercrombie, M. (1946) Estimation of nuclear populations from microtome sections. Anat. Rec. 94: 239-247.

Aguayo, A. J., L. C. Terry, and G. M. Bray (1973) Spontaneous loss of axons in sympathetic unmyelinated nerve fibers of the rat during development. Brain Res. 54: 360-364.

Black, I. B., I. A. Hendry, and L. L. Iversen (1971) Trans-synaptic regulation of growth and development of adrenergic neurons in a mouse sympathetic ganglion. Brain Res. 34: 229-240.

Brooks-Fournier, R., and R. E. Coggeshall (1981) The ratio of preganglionic axons to postganglionic cells in the sympathetic nervous system of the rat. J. Comp. Neurol. 197: 207-216.

Chan, M., A. J. Sefton, and R. A. L. Dampney (1983) Development of autonomic preganglionic nuclei in the neonatal rat. Neurosci. Lett. 11: S34.

Cochard, P., M. Goldstcin, and I. B. Black (1979) Initial development of the noradrenergic phenotype in autonomic neuroblasts of the rat embryo in vivo. Dev. Biol. 71: 100-114.

Coughlin, M. D., M. D. Dibner, D. M. Boyer, and I. B. Black (1978) Factors regulating development of an embryonic mouse sympathetic ganglion. Dev. Biol. 66: 513-528.

Dalsgaard, C. J., and L. G. Elfvin (1979) Spinal origin of preganglionic fibers projecting onto the superior cervical ganglion and inferior mesenteric ganglion of the guinea-pig. as demonstrated by the horseradish peroxidase technique. Brain Res. 172: 139-143.

Hanker, J. S., P. E. Yates, C. B. Metz, and A. Rustioni (1977) A new, specific, sensitive and non-carcinogenic reagent for the demonstration of horseradish peroxidase. Histochem. J. 9: 789-792.

Lance-Jones, C., and L. Landmesser (1981) Pathway selection by chick lumbosacral motoneurons during normal development. Proc. R. Soc. Lond. (Biol.) 214: 1-18.

Landmesser, L. (1978) The distribution of motoneurones supplying chick hind limb muscles. J. Physiol. (Lond.) 284: 371-389.

Levi-Montalcini, R. (1950). The origin and development of the visceral system in the spinal cord of the chick embryo. J. Morphol. 86: 253-284.

Lichtman, J. W., and D. Purves (1980) The elimination of redundant preganglionic innervation to hamster sympathetic ganglion cells in early post-natal life. J. Physiol. (Lond.) 301: 213-228.

Lichtman, J. W., D. Purves, and J. W. Yip (1979) On the purpose of selective innervation of guinea-pig superior cervical ganglion cells. J. Physiol. (Lond.) 292: 69-84W.

Lichtman, J. W., D. Purves, and J. W. Yip (1980) Innervation of sympathetic neurones in the guinea-pig thoracic chain. J. Physiol. (Lond.) 298: 285299.

Murata, Y., H. Shibata, and T. Chiba (1982) A correlative quantitative study comparing the nerve fibers in the cervical sympathetic trunk and the locus of the somata from which they originate in the rat. J. Autonom. Nerv. Syst. 6: 323-333.

Nadelhaft, I., W. C. DeGroat, and C. Morgan (1980) Location and morphology of parasympathetic preganglionic neurons in the sacral spinal cord of the cat revealed by retrograde axonal transport of horseradish peroxidase. J. Comp. Neurol. 193: 265-281.

Njå, A., and D. Purves (1977a) Specific innervation of guinea-pig superior cervical ganglion cells by preganglionic fibres arising from different levels of the spinal cord. J. Physiol. (Lond.) 264: 565-583.

$\mathrm{Njå,} \mathrm{A.,} \mathrm{and} \mathrm{D.} \mathrm{Purves} \mathrm{(1977b)} \mathrm{Re-innervation} \mathrm{of} \mathrm{guinea-pig} \mathrm{superior} \mathrm{cervical}$ ganglion cells by preganglionic fibres arising from different levels of the spinal cord. J. Physiol. (Lond.) 272: 633-651.

Njå, A., and D. Purves (1978) Specificity of initial synaptic contacts made on guinea-pig superior cervical ganglion cells during regeneration of the cervical sympathetic trunk. J. Physiol. (Lond.) 281: 45-62.

Nornes, H. O., and G. D. Das (1974) Temporal pattern of neurogenesis in spinal cord of rat. I. An autoradiographic study-Time and sites of origin and migration and settling patterns of neuroblasts. Brain Res. 73: 121138.

Oppenheim, R. W., J. L. Maderdrut, and D. J. Wells (1982) Cell death of motoneurons in the chick embryo spinal cord. Vl. Reduction of naturally occurring cell death in the thoracolumbar column of Terni by nerve growth factor. J. Comp. Neurol. 210: 174-189.

Perri, V., O. Sacchi, and C. Casella (1970) Synaptically mediated potentials elicited by the stimulation of post-ganglionic trunks in the guinea-pig superior cervical ganglion. Pflugers Arch, 314: 55-67.

Purves, D., and J. W. Lichtman (1980) Elimination of synapses in the developing nervous system. Science 210: 153-157.

Purves, D., W. Thompson, and J. W. Yip (1981) Re-innervation of ganglia 
transplanted to the neck from different levels of the guinea-pig sympathetic chain. J. Physiol. (Lond.) 313: 49-63

Rando, T. A., C. W. Bowers, and R. E. Zigmond (1981) Localization of neurons in the rat spinal cord which project to the superior corvical ganglion. J. Comp. Neurol. 196: 73-83.

Rubin, E. (1982) Embryonic development of the rat superior cervical ganglion. Soc. Neurosci. Abstr. 8: 6.

Rubin, E. (1983) The accurate initial outgrowth of sympathetic preganglionic axons in the embryonic rat. Soc. Neurosci. Abstr. 9: 1045.

Rubin, E. (1985a) Development of the rat superior cervical ganglion: Ganglion cell maturation. J. Neurosci. 5: 673-684

Rubin, E. (1985b) Development of the rat superior cervical ganglion: Initia stages of synapse formation. J. Neurosci. 5: 697-704.
Rubin, E., and D. Purves (1980) Segmental organization of sympathetic preganglionic neurons in the mammalian spinal cord. J. Comp. Neurol. 192: 163-174.

Schäfer, T., M. E. Schwab, and H. Thoenen (1983) Increased formation of preganglionic synapses and axons due to a retrograde trans-synaptic action of nerve growth factor in the rat sympathetic nervous system. J. Neurosci. 3: 1501-1510.

Schramm, L. P., J. M. Stribling, and J. R. Adair (1976) Developmental reorientation of sympathetic preganglionic neurons in the rat. Brain Res. 106: 166-171.

Smith, C. L., and M. Hollyday (1983) The development and postnatal organization of motor nuclei in the rat thoracic spinal cord. J. Comp. Neurol. 220: 16-28. 